\title{
Income, inequality, and subjective well-being: an international and inter- temporal perspective using panel data
}

\author{
By Carola Gruen (Washington, DC) and Stephan Klasen (Göttingen)
}

\section{Introduction}

The topic of inequality has been studied by economists and economic historians for decades. Important debates exist about levels and trends in inequality and their causes, in which the Kuznets Hypothesis of inequality - which stipulates that economic inequality first increases then decreases as a country develops economically - has received a great deal of attention, both by development economists and economic historians. ${ }^{1}$

Recently, a second body of literature has developed, in which economists have started to broaden conceptions of welfare and moved beyond income-based measures of well-being. One direction that this literature has taken has been to investigate subjective well-being or happiness as an indicator of well-being. Indeed, this research has generated a great deal of interest, particularly since it has been able to find clear stylized facts about the key drivers of well-being, both at the individual and at the societal level.

There have been some attempts to bring these two literatures on drivers of inequality and determinants of subjective well-being together and investigate the extent to which inequality has an impact on subjective well-being. In so doing it becomes clear that the relationship between inequality and subjective well-being is rather complex, and depends greatly on the way in which inequality is studied in these analyses. In particular, the overall level of inequality may have an effect on the reported subjective well-being of individuals. But this effect may also depend on attitudes towards inequality and, importantly, one's position within the different levels of income distribution.

This paper briefly summarizes the existing body of literature on this topic and then presents new quantitative results on the linkages between absolute income levels, relative incomes, income inequality, and attitudes towards redistribution in a large sample of countries over the past 30 years. We distinguish in our analyses between high-income countries, transition countries (Eastern Europe and former Soviet Union) and developing countries, since the drivers and temporal trends in subjective well-being differ between them. Our results first confirm the known facts about the role of individual factors affecting subjective well-being, including the role of unemployment, education, age, and marital status. We also confirm the significant but very small effect of absolute income levels on well-being. In terms of the role of inequality, we first note that relative income levels are of great significance to subjective well-being, particularly in transition and developing countries. We also find that preferences for inequality are a significant driver of well-being. Those who are in favor of greater income differences within a country report greater subjective well-being, and this appears to be independent of the position they are actually in (i.e. whether they are richer or poorer themselves). Lastly, we observe that overall inequality in a country has an additional negative

1 E.g. K. Deininger/L. Squire, New Ways of Looking at Old Issues. Inequality and Growth, in: Journal of Development Economics 57/2, 1998; P. Lindert/J. Williamson, American Inequality. A Macroeconomic History, New York 1980. 
effect on well-being in all three country-groupings. On the whole this suggests that inequality has a rather strong negative impact on well-being. In fact, depending on the context, reducing inequality can do more to promote subjective well-being than increasing economic growth can.

\section{Subjective well-being, income and income inequality}

In the past, subjective quality of life has predominantly been a research subject confined to psychologists and sociologists. Based on small and sometimes non-representative samples, early studies focused on the effect of unemployment, ${ }^{2}$ health and marriage. ${ }^{3}$ In a similar vein, investigating the personal characteristics of "the satisfied" has been of interest to researchers for a long time. ${ }^{4}$

Today, many developing and developed countries conduct large-scale household surveys on a regular basis and collect data at the individual and household level. In addition to personal information and standard economic variables, quality of life aspects are also covered, such as overall life and job satisfaction, subjective health indicators etc. This wealth of data has made it feasible to study levels, trends and determinants of subjective well-being in many countries across the world and has led to interesting results, sometimes with significant implications for the discipline of economics. ${ }^{5}$

The relationship between income and life satisfaction has been one of the focal points of this research. Early studies which often relied on cross-sectional data suggested that although richer people report to be happier than their less well-off peers within a country at a given time, in the long run the correlation between income growth and change in life satisfaction is rather weak, or sometimes even absent. ${ }^{6}$ This raised the question as to whether the traditional indicator of welfare, GDP per capita, is in fact a reliable and meaningful measure of progress.

The strong positive association between individual income and life satisfaction at a particular point in time and place has been confirmed for many countries at different developmental stages. Also, when comparing subjective well-being indicators across countries, satisfaction scores do increase with average income; but the increments are rather modest. Many studies also identify a threshold beyond which income seems to contribute less to happiness. ${ }^{7}$ Regarding the long term relationship, however, no consensus has been reached yet. Many studies, some also applying more appropriate longitudinal data ${ }^{8}$ have replicated the early result, showing little if no correlation between national income growth and change in life

2 M. Jahoda, Marienthal. The Sociography of an Unemployed Community, Leipzig 1933.

3 E.g. S. Orden/N. Bradburn, Dimensions of Marriage Happiness, in: American Journal of Sociology 73, 1968, pp.715-731.

4 E.g. A. Cantril, The pattern of Human Concerns, New Brunswick 1965.

5 E.g. B. Frey/A. Stutzer, What Can Economists Learn from Happiness Research?, in: Journal of Economic Literature 40/2, 2002, pp. 402-435.

6 E.g. R. Easterlin, Does Economic Growth Improve the Human Lot?, in: P.A. David/M.W. Reder (Eds.), Nations and Households in Economic Growth. Essays in Honor of Moses Abramovitz, New York 1974.

7 E.g. R. Easterlin/L. Angelescu, Happiness and Growth the World Over. Time Series Evidence on the Happiness-income Paradox (Discussion Paper IZA, 2009 No. 4060).

8 See for example R. Di Tella/J. Haisken-DeNew/R. MacCulloch, Happiness Adaptation to Income and to Status in an Individual Panel, in: Journal of Economic Behavior \& Organization 76/3, 2010, pp. 834-852 who, using individual panel data for West Germany covering the years 1984-2000, show that a change in income has no significant impact on happiness after the fourth year. 
satisfaction. But there are also a number of studies which provide evidence that higher income goes hand in hand with higher satisfaction scores. ${ }^{9}$ For example, Stevenson and Wolfers ${ }^{10}$ as well as Deaton ${ }^{11}$ make use of the Gallup World Poll data, an ongoing survey which started in 2005 and interviews people in more than 130 countries, and cannot identify a significant income threshold between poorer and richer nations. This implies that economic growth will increase life satisfaction in a similar way in any country, regardless of the actual income level. Both studies conclude that income growth will have a lasting (but modest) effect on life satisfaction. This result has been disputed in particular by Easterlin and Angelescu. ${ }^{12}$ Their own analysis of the long term dynamics between income and happiness, using a larger set of countries than Easterlin's original paper, again finds no correlation and confirms the paradox. It seems that only the arrival of genuine long term time series data on subjective well-being indicators will allow a conclusive answer. Despite the debate, all studies suggest that the impact of absolute income growth on subjective well-being, if it is present at all, is rather modest.

An uncontroversial result arising from this literature is that subjective well-being responds to macroeconomic shocks such as inflation, unemployment and output changes. ${ }^{13}$ Since recovery from severe shocks is likely to take years, there is a risk of confusing "a short-term positive association of life satisfaction and GDP per capita with the long-term trend relationship". ${ }^{4}$

The Easterlin paradox led not only to numerous studies analyzing the short and long term relationship between income and happiness, but stimulated further research into the role of relative incomes, as well as aspirations and adaptation processes. According to this line of research, the incompatible results can easily be reconciled by allowing for relative income terms in the individual utility function of economic agents..$^{15}$ In fact, one of the main determinants of individual life satisfaction is relative income. ${ }^{16}$ As has been shown in many empirical studies, individual welfare is positively influenced by the person's own income and negatively by the income of a reference group. Which effect prevails seems to vary according to the actual research context, ${ }^{17}$ but clearly has important policy implications.

A related question is whether the overall degree of income inequality within a society, measured for example by the Gini coefficient, is also a significant determinant of individual

9 For a recent survey of the long run income-happiness relationship, please refer to A.E. Clark/C. Senik, Will GDP Growth Increase Happiness in Developing Countries? (Discussion Paper IZA No. 5595, 2011).

10 B. Stevenson/J. Wolfers, Economic Growth and Subjective Well-being: Reassessing the Easterlin Paradox, in: Brookings Papers on Economic Activity 1, 2008, pp. 1-87.

11 A. Deaton, Income, Health, and Well-being around the World. Evidence from the Gallup World Poll, in: Journal of Economic Perspective 22/2, 2008, pp. 53-72.

12 Easterlin/Angelescu, Happiness and Growth.

13 E.g. R. Di Tella/R.J. MacCulloch/A.J. Oswald, The Macroeconomics of Happiness, in: Review of Economics and Statistics 85, 2003, pp. 809-827; P. Sanfey/U. Teksoz, Life in Transition. Are People Happier after a Decade and a Half? (Paper Prepared for the 30th Genereal Conference of The International Association for Research in Income and Wealth, Portoroz, Slovenia, August 24-30, 2008).

14 Easterlin/Angelescu, Happiness and Growth, p. 9.

15 A. Clark/P. Frijters/M. Shields, Relative Income, Happiness, and Utility. An Explanation for the Easterlin Paradox and Other Puzzles, in: Journal of Economic Literature 46/1, 2008, pp. 95-144.

16 See C. Senik, Income Distribution and Well-being. What Can we Learn from Subjective Data?, in: Journal of Economic Surveys 19/1, 2005, pp. 43-63 for a survey of empirical studies testing the comparison income hypothesis in both industrialized countries and European transition countries.

17 E.g. Ibid. 
welfare, over and above the effect of relative incomes. From a theoretical point of view, there are several arguments that favor the importance of the distribution of income. ${ }^{18}$ Empirical studies on risk aversion also support the hypothesis that higher levels of inequality have a negative impact on individuals' welfare levels. ${ }^{19}$ In order to increase welfare levels, these findings would suggest that redistribution policies should be implemented. If, however, inequality was seen as a proxy for potential mobility, there may be less demand for redistribution, and the well-being of people who expect to benefit from these opportunities may be positively correlated with the level of income inequality. ${ }^{20}$

Results obtained from these lines of research have also impacted the public debate on growth, consumption and welfare. Unsatisfied with per capita income as a measure of welfare, the United Nations Development Program introduced the Human Development Index (HDI) in 1990 as a composite welfare measure, combining information on health, education, and living standards to give a broader impression of well-being in a society. ${ }^{21}$ Inspired by this work, economic historians have applied these concepts to measure broader conceptions of welfare over long periods of time. ${ }^{22}$ More recently, political leaders in France, the UK and Germany, as well as at the OECD, initiated a discourse among policy makers, academics and the general public on how to measure social progress. The Stiglitz-Sen-Fitoussi Commission highlighted the many shortcomings of per capita income, today's most widely used indicator of economic welfare. Neglecting the distribution of income was seen as a particular problem. To arrive at better measures of social progress, the Commission suggests shifting the emphasis from measuring economic production to measuring people's well-being and incorporating assessments of sustainability and also considered reported subjective well-being as an important indicator of welfare. ${ }^{23}$

Similarly, the Office for National Statistics in the UK has been mandated to measure national well-being and to identify key areas that matter most and will help to ensure that any new measure will be relevant not only to policy makers but also to the wider public. Part of the initiative was a national debate on What matters to you? Among the things that mattered

18 J. Rawls, A Theory of Justice, Cambridge 1971; A. Sen, The Welfare Basis of Real Income Comparisons, in: A. Sen (Ed.), Resources, Values, and Development, Cambridge 1984, pp. 389-551; A. Sen, Commodities and Capabilities, Cambridge 1987.

19 J. Stodder, Equity-Efficiency Preferences in Poland and the Soviet Union. Order-Reversals under the Atkinson Index, in: Review of Income and Wealth 37/3, 1991, pp. 287-299; Y. Amiel/J. Creedy/S. Hurn, Measuring Attitudes towards Inequality, in: Scandinavian Journal of Economics 101/1, 1999, pp. 83-96. For a more detailed discussion on these issues, see for example C. Gruen/S. Klasen, Growth, Inequality, and Wellbeing. Intertemporal and Global Comparisons, in: CESifo Economic Studies 49/4, 2003, pp. 617-659.

20 E.g. A. Alesina/R. Di Tella/R. MacCulloch, Inequality and Happiness. Are Europeans and Americans Different?, in: Journal of Public Economics 88/9-10, 2004, pp. 2009-2042; M. Ravallion/M. Lokshin, Who Wants to Redistribute? The Tunnel Effect in 1990s Russia, in: Journal of Public Economic 76, 2000, pp. 87-104.

21 UNDP, Human Development Report 1990, New York 1990.

22 E.g. N.F.R. Crafts, Some Dimensions of the 'Quality of Life' during the British Industrial Revolution, in: Economic History Review 50, 1997, S. 617-639; L. Prados de la Escosura, Human Development in Africa: a long-run Perspective (Universidad Carlos III de Madrid, Departeamento de Historia Económica e Instituciones, Working Paper in Economic History, September 2011).

23 J.E. Stiglitz/A. Sen/J.-P. Fitoussi, Report by the Commission on the Measurement of Economic Performance and Social Progress 2010. 
and should therefore be reflected in measures of national well-being were: health, good connections with friends and family, job satisfaction and economic security, present and future conditions of the environment, education and training. ${ }^{24}$

In Germany, the Enquete Commission on Growth, Welfare and Quality of Life was constituted at the end of 2010. It was asked to examine the importance of economic growth for the economy and society, the possibilities and limits of growth, resource use and technological progress, the regulatory framework under the aspect of sustainable development, and the role of the working environment, consumption behavior and lifestyle on the sustainability of economic activities. As a result, the Commission is expected to develop a holistic measure of well-being and social progress, which will combine indicators on economic performance, quality of life, and sustainability. ${ }^{25}$

\section{Income and inequality in transition countries}

Given the severe changes that have taken place in transition countries, it is particularly instructive to study the relationship between inequality and happiness there. Former communist countries in Europe and Central Asia began implementing market-oriented reforms more than 20 years ago, which at first resulted in severe contractions in income levels. By the mid1990s, most countries had returned to positive per capita growth rates and by 2008, the large majority of countries had surpassed their pre-transition income level. ${ }^{26}$ The impact of the recent global financial crisis varied across the region. Among CIS countries, ${ }^{27}$ growth rates were dampened and sometimes turned negative, but most economies recovered relatively quickly. The picture looks different for many new EU member states, whose outputs shrank considerably during the crisis. By 2011, the Baltic States and Slovenia were still far below their pre-crisis income level.

But it was not just economic growth that was affected by the transition; the distribution of income also changed considerably. These changes turned out to be more long-lasting and, given the low levels of inequality prior to transition, this may come less as a surprise. According to the World Income Inequality Database, ${ }^{28}$ all transition countries with the exception of Croatia experienced a rise in income inequality after the transition shock. The path to higher inequality, however, differs across the region. For some countries like Russia, Kazakhstan and Kyrgyz Republic, inequality first rose sharply but then declined somewhat after the mid-1990s. In most countries, income distribution has become more and more unequal over time and occasionally reached worrisome levels, such as in Uzbekistan with a Gini coefficient of $49.6 .^{29}$

24 Office for National Statistics UK (Ed.), Measuring National Well-being.

25 German Bundestag (Ed.), Study Commission on 'Growth, Wellbeing and Quality of Life - Paths to Sustainable Economic Activity and Social Progress in the Social Market Economy', Printed Paper 17/3853, 2010.

26 See C. Gruen/S. Klasen, Has Transition Improved Well-being?, in: Economic Systems 36/1, 2012, pp. 1130 for a comprehensive analysis of well-being in transition countries.

27 The Commonwealth of Independent States includes Armenia, Azerbaijan, Belarus, Kazakhstan, Kyrgyz Republic, Moldova, Russia, Turkmenistan, Ukraine, Uzbekistan, and Tajikistan.

28 WIID (2008): World Income Inequality Database Version 2.0c, World Institute for Development Economics Research, http://www.wider.unu.edu.

29 Gruen/Klasen, Has Transition Improved Well-being?. 
Given these drastic changes that people in transition countries had to face, it seems a worthwhile exercise to study the determinants of life satisfaction some 20 years after the initial transition shock, with a particular focus on the impact of income and its distribution. A comparative analysis of countries with less severe economic changes will allow an assessment of whether the particular circumstances in transition countries has affected subjective well-being in a different way. In particular, we will compare the group of Eastern European transition countries with a number of high income countries, as well as with a number of low and middle income developing countries.

\section{Data and empirical approach}

In order to investigate the relationship between subjective well-being, income and income inequality, we make use of several waves of the World Value Survey (WVS) and European Value Survey (EVS). In particular, we use the Integrated Data File covering the period 19812004 and append the most recent waves available from the WVS and EVS, providing data up to the year $2010 .^{30}$ In total, around 100 countries are covered by the surveys and on average 1,000 people are interviewed per country and wave, leading to a total sample of about 200,000 observations for our regression analysis. The Appendix lists the countries that are included in the different waves. ${ }^{31}$

The WVS and EVS report two widely used indicators of subjective well-being: happiness, measured on a four-step scale, and overall life satisfaction, ranging from one (dissatisfied) to ten (satisfied). In many studies that look, for example, at the determinants of subjective wellbeing, these two indicators are used interchangeably. Recent research, however, has shown that when people are asked to rate their level of happiness and life satisfaction respectively, different factors are at play in how they assess them. Happiness turns out to be a more shortterm concept and is influenced by more recent events, daily emotions etc. Life satisfaction, on the other hand, seems to better capture long-term well-being and is more strongly related to income and education. ${ }^{32}$ From this point of view, life satisfaction seems the more appropriate concept for our analysis.

As discussed in the previous section, the degree of income inequality is an important determinant of overall life satisfaction, and given the changes in inequality in Eastern European transition countries, it may be even more important in this region. Our analysis will, therefore, control for the distribution of mean incomes, using Gini coefficients which are taken from the World income inequality database..$^{33}$ Depending on the structure of the underlying

30 WVS (2006): European and World Values Surveys Four Wave Integrated Data File, 1981-2004, v.20060423, 2006; WVS (2009): Official Aggregate v.20090901, 2009. Aggregate File Producer: ASEP/JDS, Madrid; EVS (2011): European Value Survey Longitudinal Data File 1981-2008. Pre-release v.1.0.0 as of April 30, 2011.

31 Unfortunately, the sample composition changes over the years. Only six countries are included in all five time periods, 22 in four time periods, 17 in three time periods, 20 in two time periods and 31 in one time period. The most consistent sample is from transition countries where 17 (or 24) countries are included in at least three waves. The biggest sample composition changes occur in developing countries. The effect of sample composition is mostly captured by the use of country fixed effects in the regression.

32 D. Kahneman/A. Deaton, High Income Improves Evaluation of Life but not Emotional Well-being, in: Proceedings of the National Academy of Sciences 107/38, 2010, pp. 16489-16493.

33 WIID, 2008. 
survey, measures of inequality are based on different concepts of income (gross or net income, consumption) and different reference units (individual or household). In order to allow for better cross-country as well as temporal comparisons, we have harmonized the Gini coefficients using a regression based approach. ${ }^{34}$

Returning to the individual-level data used in our analysis, the WVS also inquires about the satisfaction with the level of income inequality. In particular, respondents are asked to comment on the following statement on a scale from one to ten:

\section{one - Income should be made more equal \\ $\cdots$ \\ ten - We need larger income differences as incentives.}

Hence, the data provides us with a preference for inequality or equality, measured at the individual level. We will use this information to complement our analysis of determinants of life satisfaction.

In the analysis, we will also control for the known individual factors that the literature has identified as affecting inequality trends. They include the relative income level (where households place themselves in three groups: low, middle, and high income), the age and sex of the respondent, labor-market status, and marital status. We also include fixed effects for countries and the different waves of the WVS/EVS to capture common time trends. Thus we are ultimately able to specify a panel linear regression model (with country and time fixed effects) that tries to explain the self-rated subjective well-being using these individual factors, time and country effects, income levels, relative incomes, income inequality, and inequality preferences. As stated above, we do this separately for the three country groupings. One should point out that there are further individual and aggregate factors that have been found to affect well-being, such as the weather, recent life events, the time of year, time of day, among others. As long as these factors do not systematically vary with the covariates of interest here, they should not, however, bias our results. ${ }^{35}$

\section{Results}

Table 1 first provides an overview of the descriptive statistics used later in the regression analysis. In the upper panel, the table is sorted by the three country groupings, while in the lower part it is sorted by the time period to examine temporal trends. In the upper panel, a few points are worth noting. Firstly, average levels of life satisfaction are higher in high income countries than in the other two groups, presumably linked to their substantially higher per capita incomes. This seems to confirm that higher per capita incomes are associated with higher subjective well-being in a cross-section. Of particular note, however, is the low level of life satisfaction in transition countries, which is the lowest among the three groups despite

34 For a more detailed description of the harmonization, please refer to C. Gruen/S. Klasen, Growth, Inequality and Welfare. Comparisons Across Space and Time, in: Oxford Economic Papers 60, 2008, pp. 212236 and Gruen/Klasen, Has Transition Improved Well-being?.

35 See J. Weimann/A. Knabe/R. Schöb, Geld macht doch glücklich. Wo die ökonomische Glückforschung irrt, Stuttgart 2012 for a discussion of some of these issues. Similarly, there may well be measurement error which should, however, not affect our results if it is similarly uncorrelated with the key explanatory variables. 
incomes being much higher in transition than in developing countries. Clearly, there is something special about transition countries or the transition process that has been associated with low levels of subjective well-being, a subject analyzed in detail by Gruen and Klasen. ${ }^{36}$ Secondly, there are some differences regarding inequality. In high-income and transition countries, inequality is substantially lower than in developing countries; on the other hand, the preference for inequality is slightly higher in transition and developing countries than in

Table 1a: Summary Statistics by Income Group

\begin{tabular}{|l|ll|ll|ll|}
\hline Variable & \multicolumn{3}{|l|}{ High income countries } & \multicolumn{2}{l|}{ Transitional countries } & \multicolumn{2}{l|}{ Other countries } \\
\hline & Mean & SD & Mean & SD & Mean & SD \\
\hline Life satisfaction & 7.437 & 1.947 & 5.871 & 2.501 & 6.574 & 2.549 \\
Income p.c. & 29994 & 8342 & 9772 & 5414 & 5989 & 3597 \\
Gini coefficient & 35.32 & 12.17 & 34.21 & 7.71 & 49.19 & 8.05 \\
Low income & 0.337 & 0.473 & 0.344 & 0.475 & 0.375 & 0.484 \\
Middle income & 0.364 & 0.481 & 0.367 & 0.482 & 0.347 & 0.476 \\
High income & 0.299 & 0.458 & 0.290 & 0.454 & 0.278 & 0.448 \\
Income equality preference & 5.592 & 2.728 & 5.965 & 2.972 & 5.946 & 3.203 \\
By income & & & & & & \\
Low & 5.17 & 2.80 & 5.62 & 3.06 & 5.63 & 3.31 \\
Middle & 5.56 & 2.71 & 5.99 & 2.94 & 5.94 & 3.15 \\
High & 6.10 & 2.57 & 6.34 & 2.86 & 6.37 & 3.08 \\
& 45.36 & & & & & \\
Age & 2 & 16.941 & 44.313 & 16.635 & 37.249 & 14.334 \\
Male & 0.480 & 0.500 & 0.456 & 0.498 & 0.508 & 0.500 \\
Full time emp. & 0.435 & 0.496 & 0.444 & 0.497 & 0.306 & 0.461 \\
Part time emp. & 0.086 & 0.281 & 0.053 & 0.224 & 0.074 & 0.261 \\
Self-employed & 0.061 & 0.239 & 0.050 & 0.219 & 0.154 & 0.361 \\
Retired & 0.185 & 0.389 & 0.220 & 0.414 & 0.057 & 0.232 \\
Housewife & 0.112 & 0.315 & 0.060 & 0.237 & 0.192 & 0.394 \\
Student & 0.049 & 0.215 & 0.052 & 0.222 & 0.090 & 0.286 \\
Unemployed & 0.051 & 0.221 & 0.103 & 0.304 & 0.105 & 0.307 \\
Other & 0.021 & 0.144 & 0.018 & 0.134 & 0.022 & 0.147 \\
Married & 0.570 & 0.495 & 0.620 & 0.485 & 0.569 & 0.495 \\
Living together & 0.055 & 0.228 & 0.022 & 0.145 & 0.072 & 0.258 \\
Divorced & 0.059 & 0.236 & 0.058 & 0.233 & 0.017 & 0.128 \\
Separated & 0.020 & 0.140 & 0.011 & 0.104 & 0.018 & 0.134 \\
Widowed & 0.068 & 0.252 & 0.101 & 0.301 & 0.042 & 0.202 \\
Single & 0.227 & 0.419 & 0.189 & 0.392 & 0.282 & 0.450 \\
\hline
\end{tabular}

36 Gruen/Klasen, Has Transition Improved Well-being? 


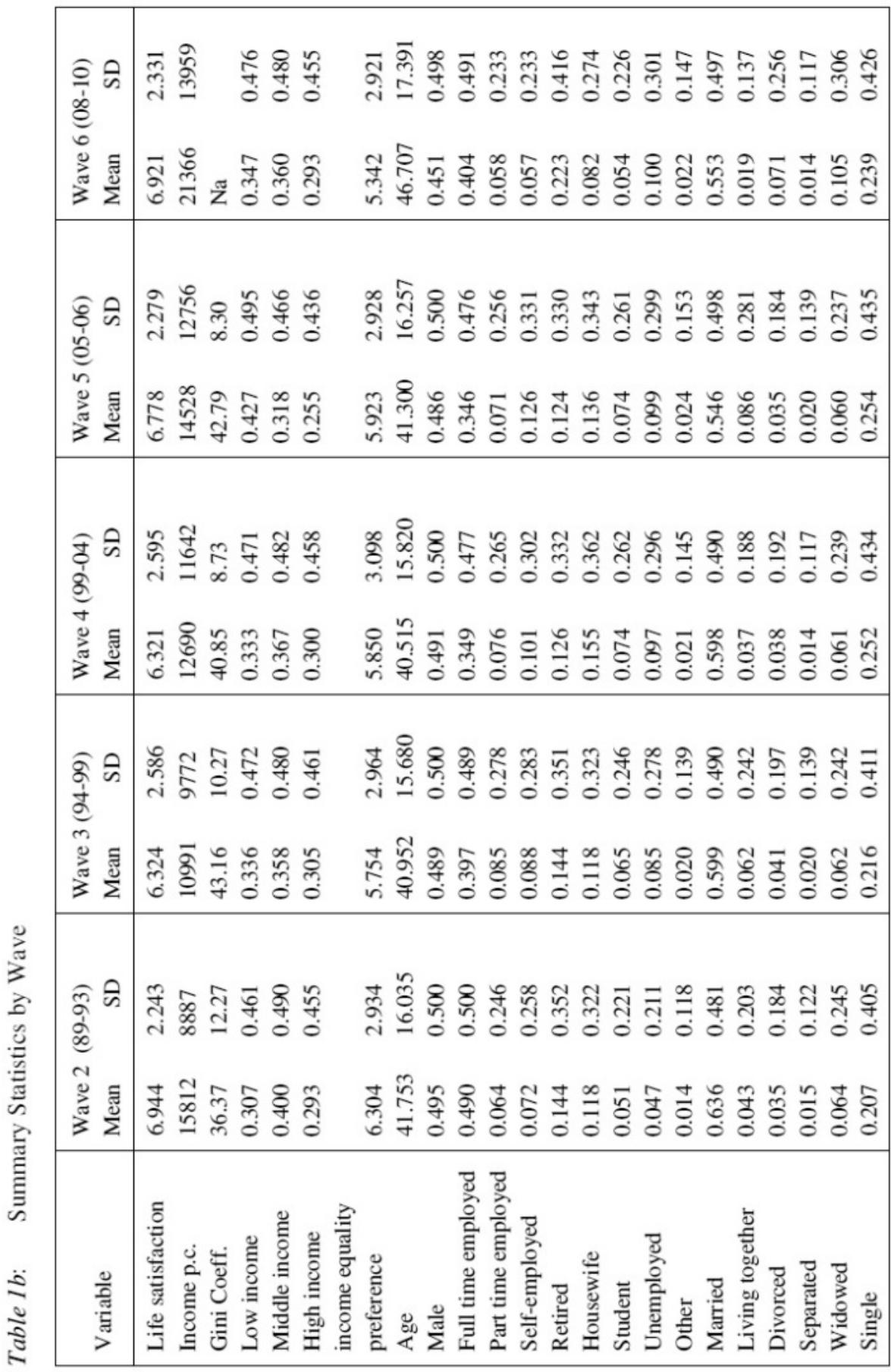


high-income countries. Noteworthy but not terribly surprising is also the fact that the preference for inequality is higher among higher income groups in all three country groupings, although the difference is not very large. Thirdly, other differences between the three country groups are relatively small, including marital status and size of income groups. Of some note is that the average age of respondents is lower in developing countries, the share of unemployed respondents is higher in transition and developing countries, and a larger share of respondents in developing countries are students.

The bottom panel of Table 1 reveals some noteworthy trends in subjective well-being. The first point of note is that there are no clear trends in subjective well-being over time. While this is partly related to differences in sample composition between the time groups, it also confirms the finding above that rising incomes lead, at best, to modest increases in subjective well-being over time. Income trends are also not so clear. The decline in average incomes in wave three (1994-1999) is related to the drastic income collapse in transition countries in the early phases of the transition process. Other than that, the data identifies some known trends in individual characteristics over time. The share of married respondents has declined while the share of retired respondents has increased. There are no clear trends in equality preference over time. While these results are interesting, it is important to test whether these finding hold up in our multivariate panel regression framework, to which we now turn our attention.

Table 2 shows our first specification of the regression analysis for the whole sample and the three country groupings. We will focus the discussion particularly on the regressions for the three country groups, as the regressions for the overall sample average out diverging trends in the different regions and might therefore be somewhat less informative. While the regressions generally confirm the importance of some personal characteristics to subjective well-being, the magnitude and significance of the effects differ considerably between the country groupings. In high-income countries, we reproduce the known findings of a U-shaped age effect, with lowest levels of subjective well-being in middle age. Married people report substantially higher well-being, while divorced, separated, and widowed respondents report much lower levels of well-being. Unemployed people are also much worse off than those who are employed full-time and women report slightly higher levels of subjective well-being than men. There appear to be no significant time trends. In transition countries, there are important differences with regard to these effects. First, the age effect looks rather different, with the youngest generation of respondents reporting the highest levels of well-being. Thus it appears that the older generations do not feel they have benefited much from the transition process. Compared to the full-time employed, the unemployed are also worse off, but the penalty is less severe. Conversely, students, those who are employed part-time or who are self-employed are better off than those in full-time employment, and retired people are worse off. Clearly, employment status has a differentiating impact on well-being in transition countries as elsewhere. Marital status effects are rather similar, but the gender effect is not significant. Of particular note is also the different time trend. There is a very clear U-trend in subjective well-being in transition countries which reached the lowest level in wave three, referring to the mid- to late 1990s. In developing countries, the individual effects are much more similar to high-income countries, while the time trends also show a dip in the mid- to late 1990s.

Moving on to the effects of relative incomes and inequality, the specifications in Table 2 consider the influence of income brackets, equality preferences, and the interaction between 


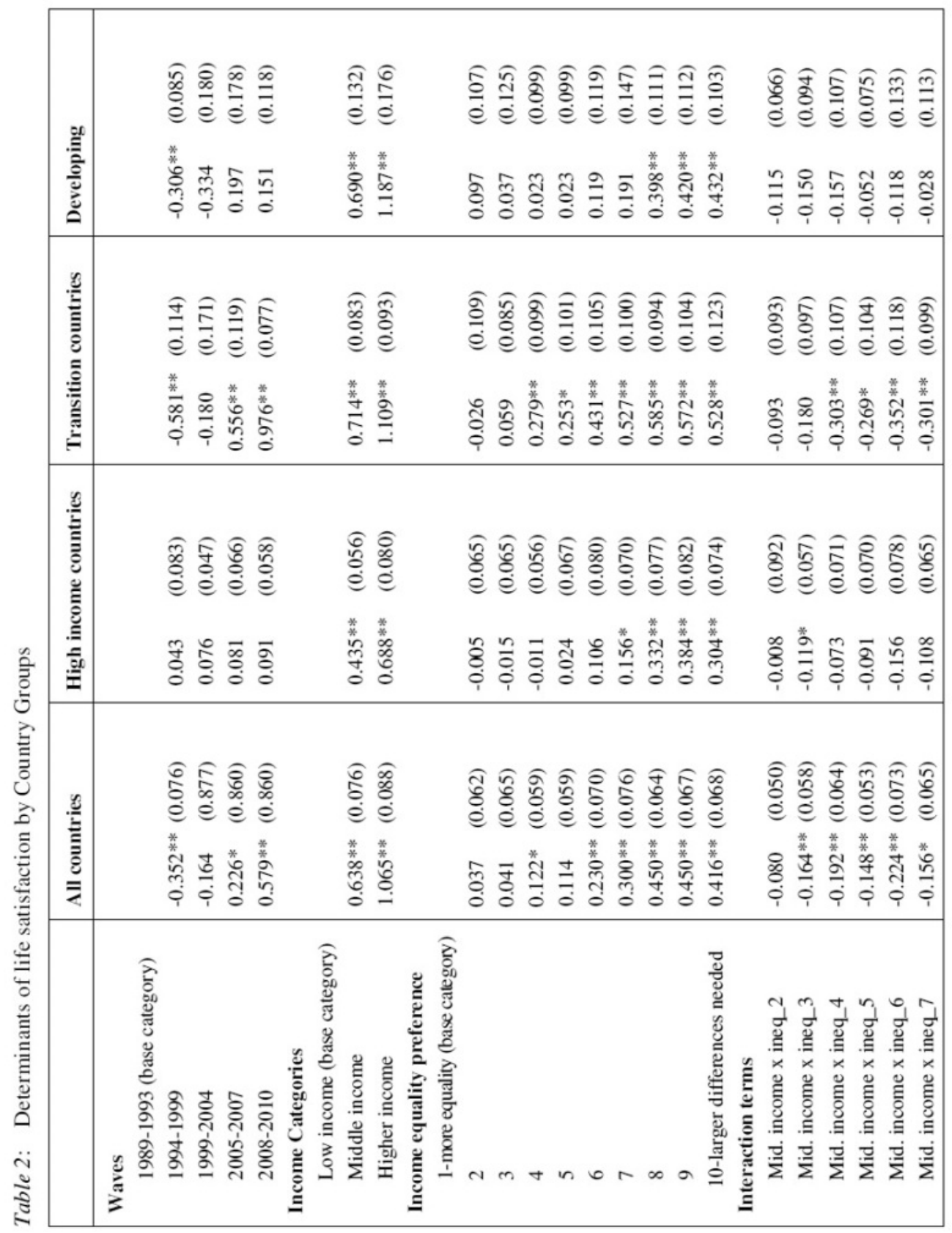




\begin{tabular}{|c|c|c|c|}
\hline 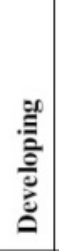 & 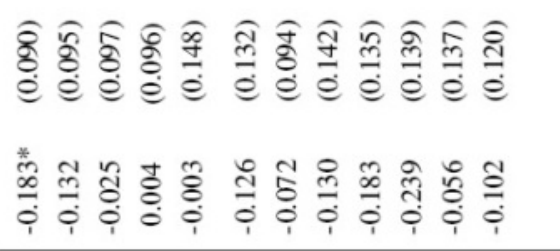 & 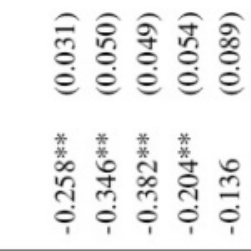 & 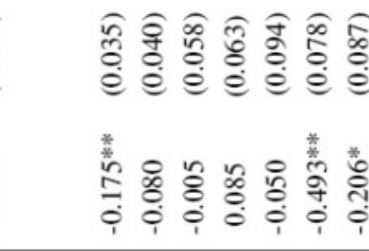 \\
\hline 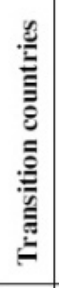 & 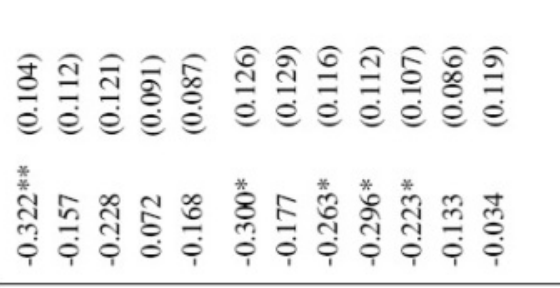 & 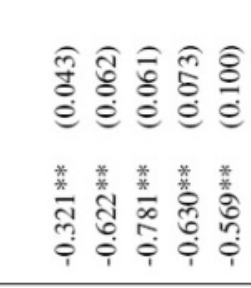 & 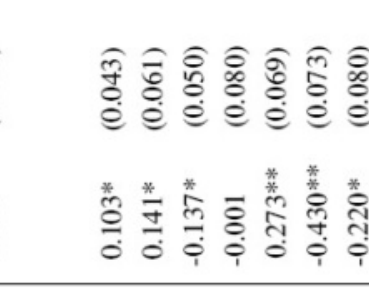 \\
\hline 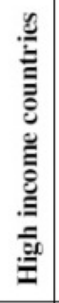 & 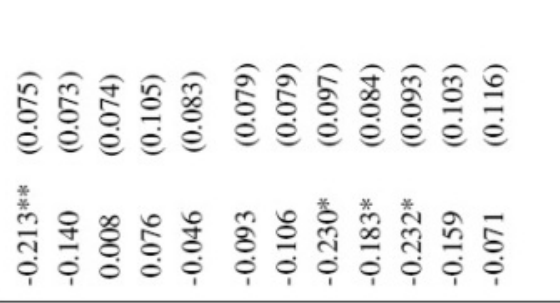 & 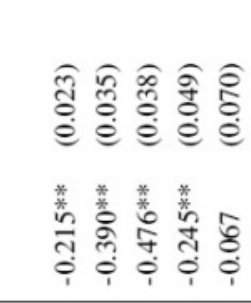 & 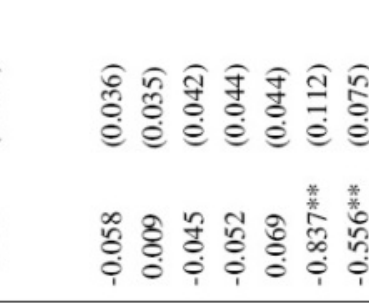 \\
\hline 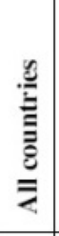 & 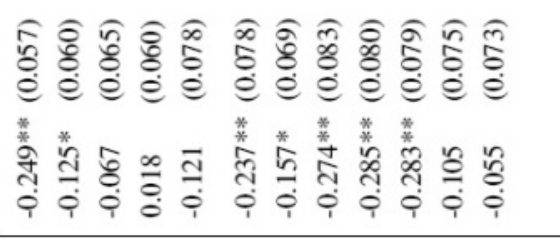 & 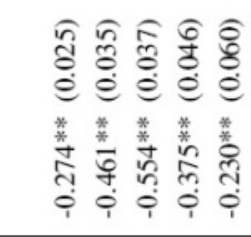 & 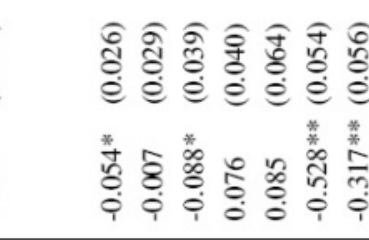 \\
\hline & 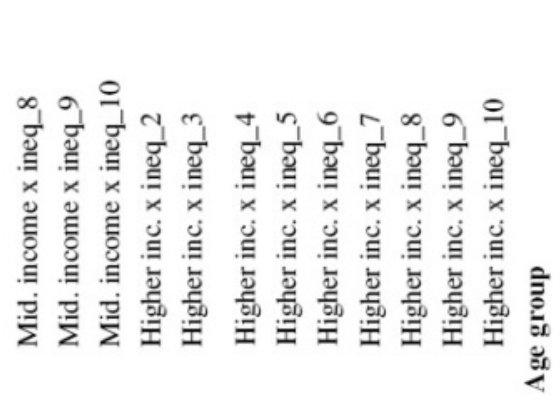 & 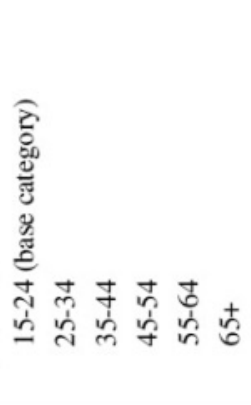 & 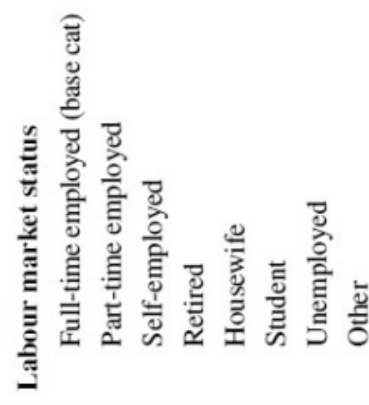 \\
\hline
\end{tabular}




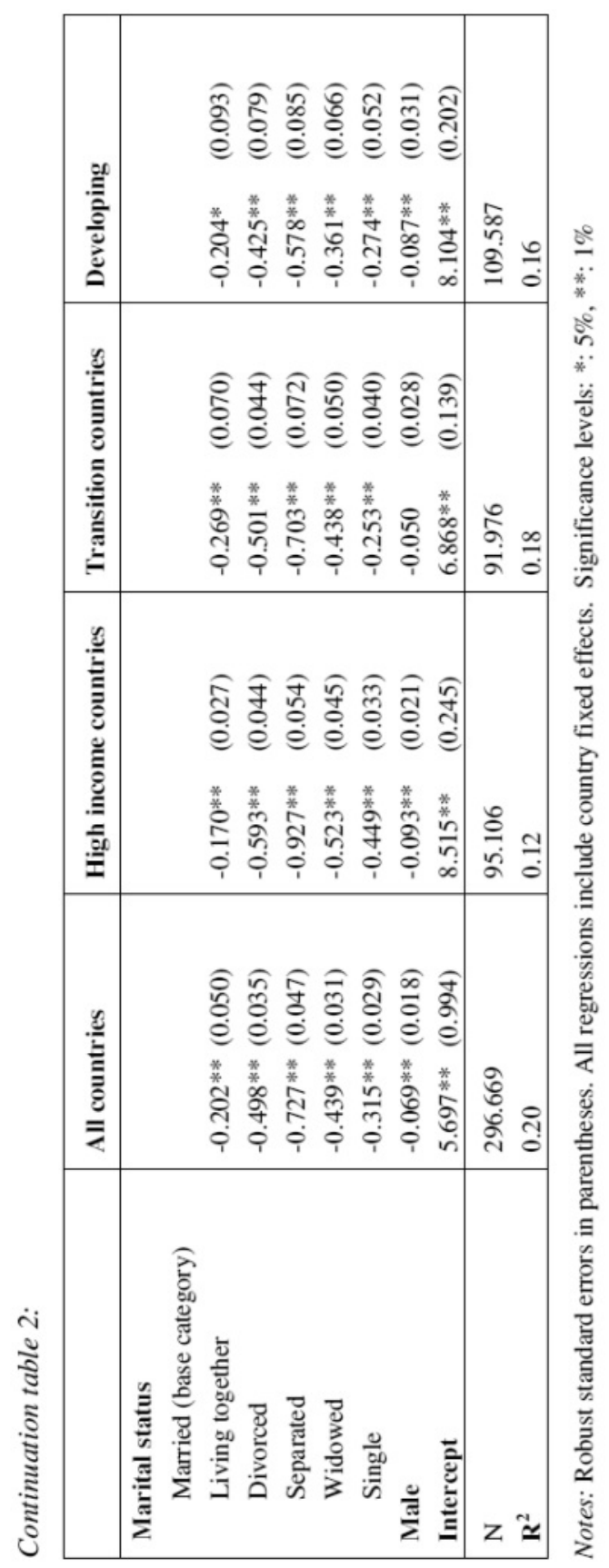


the two. The results clearly show the large effects of (relative) income position. As one moves from low to middle and high income groups, subjective well-being increases substantially. This effect is particularly strong in transition and developing countries, suggesting that relative incomes matter even more there than in high-income countries. In all three country groups, equality preferences affect subjective well-being. Those who feel that larger income differences are needed report higher levels of subjective well-being. This effect is most pronounced in transition countries. The interaction effect is often not significant. Only in transition countries does it appear to be the case that the respondents from middle and higher income groups who feel that more differentiation is needed actually report lower levels of well-being; this could suggest that insufficient differentiation felt among middle and higher income groups is a source of the (slightly) lower reported well-being. However, this effect is not present among those who want strong differentiation (answering 9 or 10 on the inequality preference scale), and it is not stronger among the higher than the middle income groups, and is easily dominated by the larger effect of relative incomes.

These results suggest overall that relative incomes matter a great deal, as do inequality preferences for subjective well-being, with particularly strong effects in transition and developing countries. Also of note is that a higher share of high-income households reported a greater preference for inequality. Thus inequality seems, to some extent, to generate its own support, as those favored by it support greater inequality.

In Table 3, we focus on the influence of total inequality on subjective well-being. While the effect of relative incomes remains largely unchanged, overall inequality has a significant negative impact on subjective well-being in all three country groups, with the largest coefficient in developing countries. Clearly, overall inequality reduces average well-being of people in the country, over and above the effects of individual relative incomes. The effect is, however, not very large in magnitude. A ten-point increase in the Gini coefficient would reduce subjective well-being by between 0.16 and 0.38 on the ten point scale subjective wellbeing scale, which is much smaller than the effect of being unemployed or belonging to the lower income group.

In Table 4, we add average per capita incomes to Table 3's specification to control for the effect of average prosperity. Since we are including country fixed effects, the coefficient effectively measures whether increases in average incomes in a country affect subjective well-being. Interestingly, income growth leads to higher subjective well-being in all three country groupings. The effect is, however, very small in high-income countries, substantially larger in transition countries, and even larger in developing countries. This confirms the notion discussed above that, as incomes rise, income growth seems to have a sharply declining marginal impact on well-being. ${ }^{37}$ Including average prosperity does not change the results for relative incomes at all and also has hardly any impact on the coefficient for overall inequality. The one exception is that now in transition countries the small negative effect of inequality on well-being is no longer significant, which is presumably due to the empirical

37 Note also that we are considering relatively short time-periods and therefore our results might be subject to the problem of mixing short-term business cycle effects (which have been found to be a strong determinant of well-being) with longer-term effects of secular income increases (whose impact on subjective wellbeing is much less clear). 


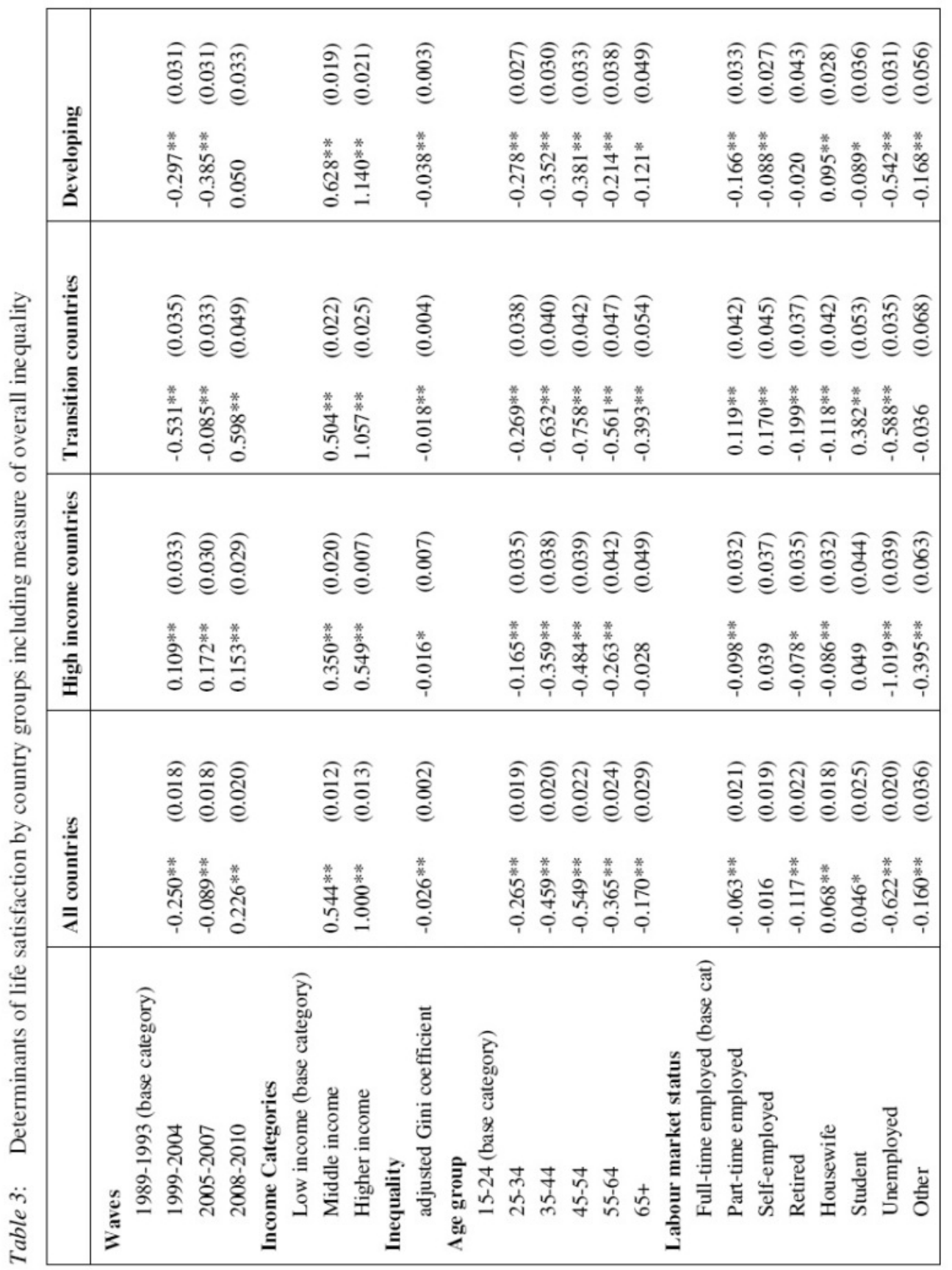




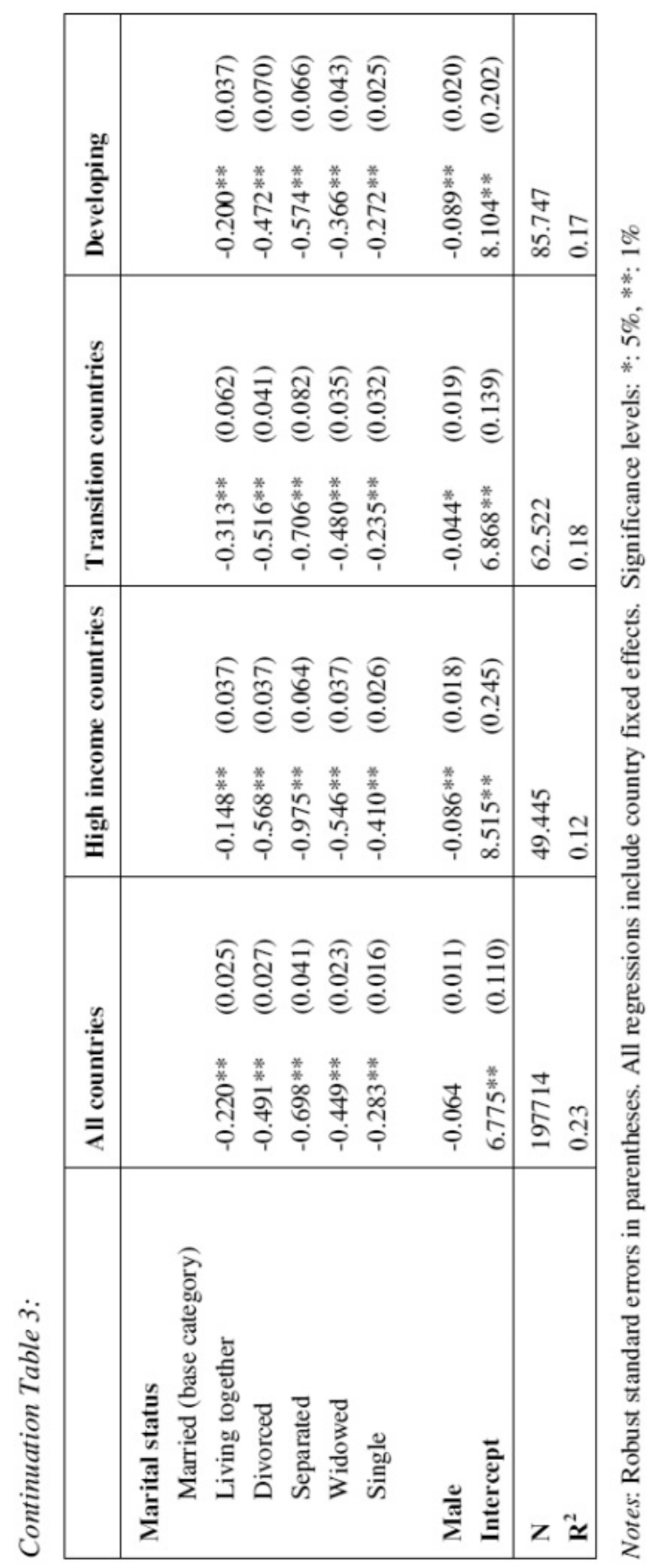




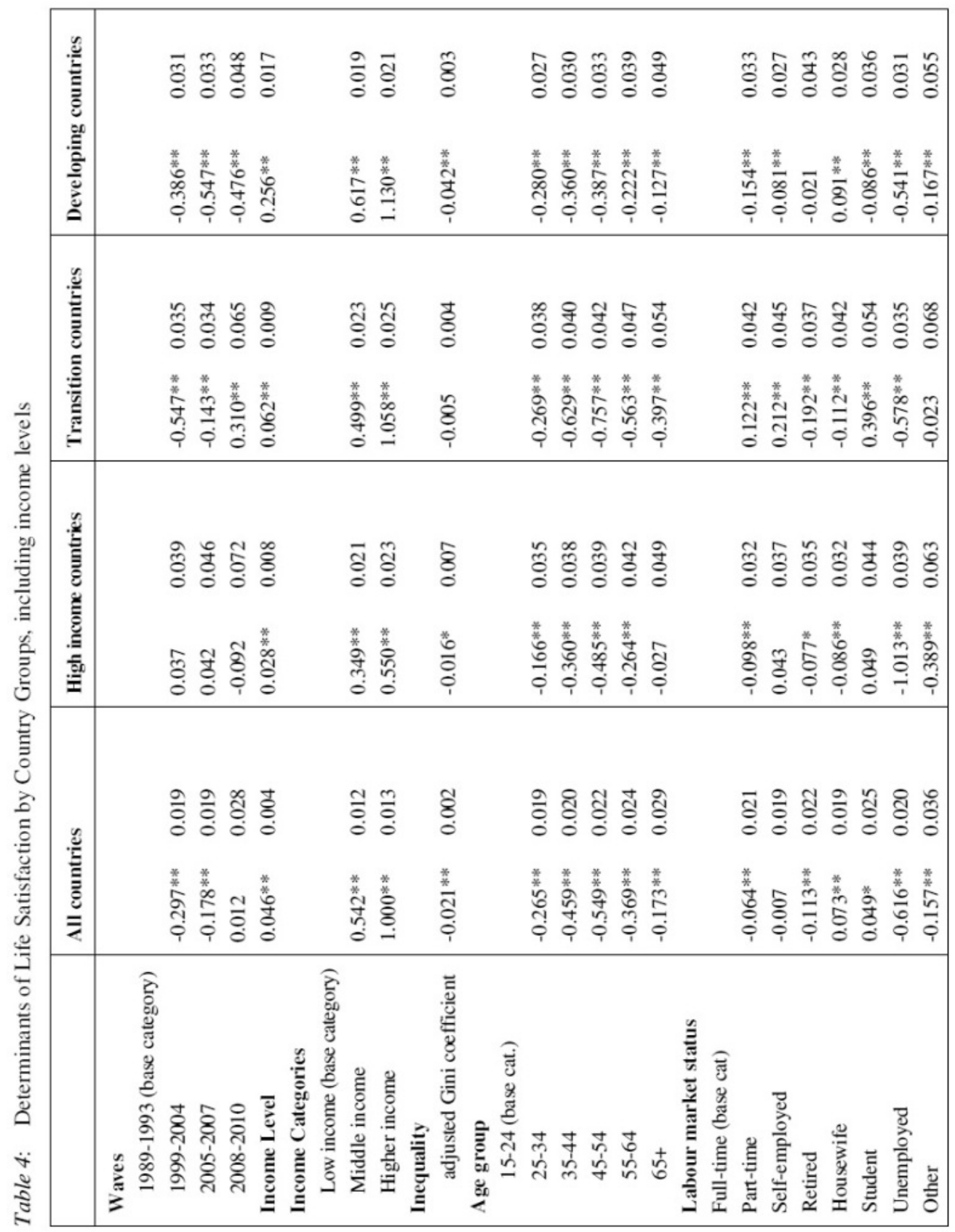




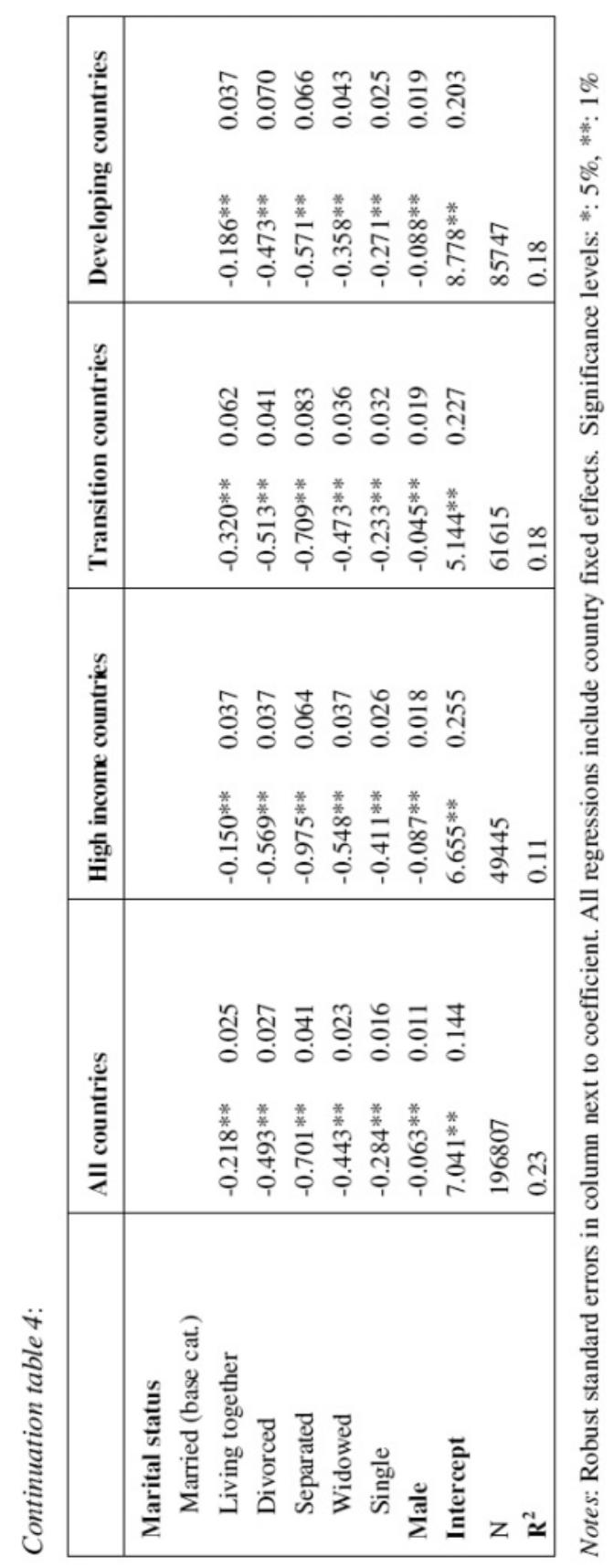


correlation of output collapse and inequality increase in transition countries during the transition process. ${ }^{38}$

Taken together, this shows that absolute incomes matter (but very little in rich countries), relative incomes matter a great deal (particularly in transition and developing countries), inequality attitudes affect well-being and are shaped by relative incomes, and inequality has an additional small negative impact on subjective well-being.

\section{Conclusion}

This paper has discussed the determinants of subjective well-being in a large sample of countries over the past 20 years. On the one hand, we are able to confirm many of the known findings on the individual determinants of subjective well-being, which are particularly visible in our sample of high-income and developing countries. In contrast, transition countries appear to display a different pattern that is closely related to the transition process which generated massive output declines in the early- to mid-1990s, where younger generations appear to have benefited disproportionately from the later recovery. We also find that inequality has a substantial impact on subjective well-being. In fact, there seem to be several effects operating at the same time. Reducing inequality would level differences in relative incomes, which are among the largest drivers of subjective well-being. In addition, it would have an effect via the overall effect of inequality and might also affect the impact of inequality preferences on overall well-being. ${ }^{39}$ When comparing the quantitative effects of income growth and reducing inequality on subjective well-being, the very small effect of income growth on well-being in high income countries suggests that in these countries reducing inequality has a substantially greater effect on well-being than promoting income growth.

38 Gruen/Klasen, Has Transition Improved Well-being?

39 There would be a rather complex third effect related to the fact that people in higher income brackets have a higher preference for inequality, which affects well-being directly and indirectly (see Table 2). These effects are, in total, however, smaller than the other effects discussed above. 
Appendix Table 1: $\quad$ List of Countries by Sample and Waves

\begin{tabular}{|c|c|c|c|}
\hline & High-Income Sample & Transition Sample & $\begin{array}{c}\text { Developing Country } \\
\text { Sample }\end{array}$ \\
\hline All five waves & Finland, Spain & Bulgaria, Romania, Russia & Turkey \\
\hline Waves $2,3,4,5$ & Japan, UK, USA & & $\begin{array}{l}\text { Chile, China, India, } \\
\text { Mexico, South Africa, }\end{array}$ \\
\hline Waves $2,3,4,6$ & & $\begin{array}{l}\text { Belarus, Czech Republic, } \\
\text { Estonia, Lithuania }\end{array}$ & \\
\hline Waves $2,3,5,6$ & Germany, Norway & & \\
\hline Waves $2,4,5,6$ & $\begin{array}{l}\text { France, Italy, } \\
\text { Netherlands }\end{array}$ & Poland, Slovenia & \\
\hline Waves $3,4,5,6$ & & Moldova, Ukraine & \\
\hline Waves 2,3 and 4 & & & Argentina, Nigeria \\
\hline Waves 2,3 and 5 & & & Brazil \\
\hline Waves 2,3 , and 6 & & Latvia, Slovakia & \\
\hline Waves 2,4 , and 5 & Canada & & \\
\hline Waves 2,4 , and 6 & $\begin{array}{l}\text { Austria, Belgium, } \\
\text { Iceland, Ireland }\end{array}$ & & \\
\hline Waves 3,4 , and 5 & & & Peru \\
\hline Waves 3,4 , and 6 & & $\begin{array}{c}\text { Albania, Bosnia and } \\
\text { Herzegovina, Croatia, } \\
\text { Macedonia }\end{array}$ & \\
\hline Waves 3,5 , and 6 & Sweden, Switzerland & & \\
\hline Waves 2 and 4 & Northern Ireland & & \\
\hline Waves 2 and 6 & Denmark, Portugal & Hungary & \\
\hline Waves 3 and 4 & Puerto Rico & & Bangladesh, Venezuela \\
\hline Waves 3 and 5 & & & $\begin{array}{c}\text { Taiwan, Colombia, } \\
\text { Uruguay }\end{array}$ \\
\hline Waves 3 and 6 & & Azerbaijan, Armenia & \\
\hline Waves 4 and 5 & South Korea & & $\begin{array}{c}\text { Indonesia, Iran, Egypt, } \\
\text { Morocco, Vietnam }\end{array}$ \\
\hline Waves 4 and 6 & Luxembourg & & \\
\hline Waves 5 and 6 & & Serbia & \\
\hline Wave 3 & New Zealand & & $\begin{array}{c}\text { Dominican Republic, } \\
\text { El Salvador }\end{array}$ \\
\hline Wave 4 & $\begin{array}{l}\text { Israel, Saudi Arabia, } \\
\text { Singapore }\end{array}$ & Kyrgyzstan & $\begin{array}{l}\text { Algeria, Iraq, Jordan, } \\
\text { Pakistan, Zimbabwe, } \\
\text { Uganda, Tanzania }\end{array}$ \\
\hline Wave 5 & $\begin{array}{c}\text { Andorra, Cyprus, Hong } \\
\text { Kong, Trinidad and } \\
\text { Tobago }\end{array}$ & & $\begin{array}{c}\text { Ethiopia, Ghana, } \\
\text { Guatemala, Malaysia, } \\
\text { Mali, Rwanda, } \\
\text { Thailand, Burkina } \\
\text { Faso, Zambia }\end{array}$ \\
\hline Wave 6 & Greece, Malta & Montenegro, Kosovo & \\
\hline
\end{tabular}

Note: Wave 2 refers to 1989-93, wave 3 1994-99, wave 4 99-2004, wave 5 2007-07, and wave 6 2008-10. 
Carola Gruen and Stephan Klasen: Income, inequality, and subjective well-being: an international and inter-temporal perspective using panel data

\begin{abstract}
In this paper we present new quantitative results on the linkages between absolute income levels, relative incomes, income inequality, and attitudes towards redistribution in a large sample of countries over the past 30 years. While we find that absolute income levels have a significant but very small effect on well-being, we find that relative incomes matter much more. In addition, we find that preferences for inequality are a significant driver of well-being. Lastly, we observe that overall inequality has an additional negative impact on well-being in a country in all three country-groupings. Taken together, this suggests that inequality has a rather strong negative impact on well-being. In fact, depending on the context, reducing inequality can do more to promote subjective well-being than increasing economic growth.
\end{abstract}

Keywords: life satisfaction, income, inequality, panel data

JEL-Codes: D 31, D 63, P 36

Stephan Klasen is Professor of economics at the University of Göttingen. There he also directs the Ibero-America Institute of Economic Research and the Courant Research Center 'Poverty, equity, and growth in developing and transition countries.' He holds a Ph.D. in economics from Harvard University where his dissertation (supervised by Amartya Sen and Jeff Williamson) examined episodes of gender inequality in mortality in Germany in the 17th-19th century and in today's developing countries. He has since held positions at the World Bank, King's College (UK), and the University of Munich. His research focuses on poverty and inequality issues in developing countries.

Carola Gruen is working for the Europe and Central Asia region at the World Bank, Washington, DC. She holds a PhD in Economics from the University of Munich. She has previously held positions at the University of the Witwatersrand, Johannesburg, the Institute for Employment Research, Nuremberg, and the University of Goettingen. She mainly works on poverty and welfare measurement related topics as well as labor economics in developing and transition countries.

Stephan Klasen

Professor of Economics

University of Göttingen

Platz der Göttinger Sieben 3

37073 Göttingen

Ph: +49-551-397303

sklasen@uni-goettingen.de

\section{Carola Gruen}

The World Bank

1818 H Street, NW

Washington, DC 20433

USA

cgruen@worldbank.org 